\title{
Rapid Colorimetric Determination of Methylglyoxal Equivalents for Manuka Honey
}

\author{
T. H. Kwok ${ }^{1}$, G. Kirkpatrick ${ }^{1}$, H. I. Mohd Yusof ${ }^{1}$, I. Portokalakis ${ }^{1}$, P. S. Nigam ${ }^{1}$ \\ and R. Owusu-Apenten ${ }^{1^{\star}}$
}

${ }^{1}$ School of Biomedical Sciences, Ulster University, Cromore Rd, Coleraine, BT52 1SA, UK.

Authors' contributions

This work was carried out in collaboration between all authors. Authors ROA and PSN designed the study and wrote the protocol. Authors THK, GK, IH and IP performed experimental work and managed the data analysis and produced grahics. Author ROA wrote the first draft of the manuscript. All authors read and approved the final manuscript.

Article Information

DOI: $10.9734 / J A B B / 2016 / 26592$

Editor(s):

(1) Csilla Tothova, Clinic for Ruminants, University of Veterinary Medicine and Pharmacy in Kosice,

Slovak Republic.

Reviewers:

(1) Marcondes Viana Da Silva, Southeast Bahia State University -UESB, Brazil.

(2) Ibrahim Kıvrak, Muğla Sıtkı Koçman University, Turkey.

(3) Takeshi Nagai, Graduate School of Yamagata University, Japan. (4) Satyendra Gautam, Bhabha Atomic Research Centre, Mumbai, India. Complete Peer review History: http://sciencedomain.org/review-history/15026

Short Research Article

Received $25^{\text {th }}$ April 2016

Accepted $9^{\text {th }}$ June 2016

Published 14 ${ }^{\text {th }}$ June 2016

\section{ABSTRACT}

Aims: Realization of a rapid colorimetric assay for monitoring levels of methylglyoxal and other dicarbonyl compounds from Manuka honey.

Methods: N-acetyl cysteine (NAC) and 2, 4-dinitrophenylhydrazine (DNPH) were adopted as reagents for methylglyoxal colorimetric analysis of honey at 288 or $525 \mathrm{~nm}$, respectively.

Results and Discussion: NAC and DNPH produced linear responses for methylglyoxal with:(i) regression coefficient $\left(R^{2}\right)$ equal to 0.99 or 0.97 , (ii) molar absorptivity (measure of sensitivity) equal to $287 \pm 11$ or $14189 \pm 498 \mathrm{M}^{-1} \mathrm{~cm}^{-1}$, (iii) a minimum detectable concentration (MDC) of $0.18 \mathrm{mM}$ vs $7.3 \mu \mathrm{M}$, (iv) upper linearity limit of linearity (ULL) equal to $4 \mathrm{mM}$ or $83 \mu \mathrm{M}$, and (v) a day-to-day precision of 16.0 and $18.3 \%$, respectively. Low interferences occurred with reducing sugars, glyoxal or 3-deoxy-D-glucosone. For honey with a unique manuka factor (UMF) rating 5+ to UMF18+, the net concentration of dicarbonyl compounds ranged from $1069 \mathrm{mg}$-methylglyoxal equivalence per kg (mg MeGEq $/ \mathrm{kg}$ ) to 2208 (mg MeGEq $/ \mathrm{kg}$ ) using the NAC assay. For the DNPH assay, the apparent 
dicarbonyl concentration was 350 to 1009-mg MeGEq $/ \mathrm{kg}$ honey. Measures of methylglyoxal equivalences were strongly correlated with the UMF rating for honeys ( $R 2=0.98-0.99)$.

Conclusion: The proposed colorimetric analysis of methylglyoxal equivalence in Manuka honey is feasible proposition. Further work is needed for method validation.

Keywords: Rapid determination; dicarbonyl compounds; n-acetyl cysteine; carbonyl reagents; 2, 4dinitrophenylhydrazine; methylglyoxal; 3-deoxy-D-glucosone.

\section{INTRODUCTION}

Methylglyoxal contributes to the medicinal value of Manuka honey. Dicarbonyl compounds occur also in many foods featuring Maillard browning including, fermented dairy products [1], beer, coffee, and balsamic vinegar [2]. Non-peroxide antimicrobial activity of Manuka honey is attributed to methylglyoxal [3-6] alongside of other components [7].

Routine analysis of dicarbonyl compounds in honey is by RP-HPLC analysis [3-6]. Despite its high accuracy HPLC analysis requires costly equipment. Alternative methods for screening honey samples for methylglyoxal content would be beneficial. Colorimetric analysis of methylglyoxal using n-acetylcysteine (NAC) or 2, 4-dinitrophenylhydrazine were described in the past but applications to honey have yet to be reported $[8,9]$.

The aim of this study was, to develop a rapid colorimetric assay for screening methylglyoxal levels from medicinal honey. Three colorimetric methods [8-10] were evaluated with honey. The results cited as methylglyoxal equivalence suggest that Manuka honey samples could be differentiated on the basis of colorimetric analysis.

\section{MATERIALS AND METHODS}

\subsection{Materials}

Manuka honey samples rated "Unique Manuka Factor" (UMF) 5+, UMF10+, UMF15+, UMF18+ were purchased from Comvita UK Ltd (Slough, UK) and diluted 10 -fold as used in our previous study [11]. The 3-deoxy-d-glucosone (3-DG) sample was supplied by Carbosynth Ltd (Compton, UK). Methylglyoxal (40\% solution in water), glyoxal, fructose, $\mathrm{N}$-acetyl cysteine (NAC), and 2, 4-dinitrophenylhydrazine (DNPH) and other reagents not specified otherwise were from Sigma-Aldrich Ltd.

\subsection{The N-acetyl Cysteine Assay for Methylglyoxal}

Colorimetric analysis using NAC was performed as described previously [8]. Briefly, methylglyoxal (100 mM in water; 9.4-150 $\mu \mathrm{l}$ ), 600 $\mu \mathrm{l}$ of NAC (50 mM in PBS) and sufficient PBS to bring total volume to $3000 \mu \mathrm{l}$ were reacted at $3^{\circ} \mathrm{C}$ for 30 minutes. Samples were cooled to room temperature and spectrophotometric readings were recorded at $288 \mathrm{~nm}$ using quartz cuvettes and an Ultrospec 2000 UV/VIS Spectrophotometer (Pharmacia Biotech). Honey samples $(10 \% \mathrm{v} / \mathrm{v}$ in water) were analyzed as described above. Two blank readings without honey (B1) or NAC (B2) were recorded and absorbances were corrected by subtracting $\mathrm{B} 1+\mathrm{B} 2$ from spectrophotometric readings. Unless otherwise stated, measurements were done in duplicate and repeated on at least two occasions $(n \geq 6)$.

\subsection{DNPH Methylglyoxal Method (I)}

In accordance with Gilbert and Brandt [9] carbonyl compounds $(5 \mathrm{mM}$ in deionized water, 0-100 $\mu$ l) were mixed with $900-1000 \mu \mathrm{l}$ of DNPH (0.2 $\mathrm{mM}$ in $12: 88 \mathrm{v} / \mathrm{v} \mathrm{HCl}$ - ethanol solvent) and incubated at $45^{\circ} \mathrm{C}$ for 45 minutes. Samples were cooled to room temperature and spectrophotometric readings were recorded at $432 \mathrm{~nm}$ using an Ultrospec 2000 UV/VIS Spectrophotometer (Pharmacia Biotech). Honey samples (10\% v/v in water) were analyzed as described above. To correct for background absorbances two "blanks" readings without carbonyl compound or honey (B1) and without DNPH (B2) were used.

\subsection{DNPH Alpha-keto Acid Method (II)}

Analysis using DNPH was as described previously with minor modification [10]. Briefly, test compounds $(0-10 \mathrm{mM} ; 25 \mu \mathrm{l})$ were added to deionized water $(975 \mu \mathrm{l})$ and $1000 \mu \mathrm{l}$ of DNPH reagent $(0.9 \mathrm{mM}$ in $1 \mathrm{~N} \mathrm{HCl})$ and the mixture was incubated at $37^{\circ} \mathrm{C}$ for $10 \mathrm{~min}$. Sodium hydroxide 
solution (1.5 N, $1000 \mu \mathrm{l})$ was added and readings were recorded at $525 \mathrm{~nm}$ using a Ultrospec 2000 UV/VIS Spectrophotometer (Pharmacia Biotech)..Samples of honey (10\% $\mathrm{v} / \mathrm{v}$ in water) were analyzed as described above. Sample "blanks" without the addition of honey (B1) or DNPH (B2) were used for correcting absorbance readings.

\section{RESULTS AND DISCUSSION}

Dicarbonyl compounds in honey are frequently analyzed by RP-HPLC analysis after derivatization with o-phenylinediamine [3-6]. To determine the total dicarbonyl compound concentration individual components have been quantitated. Each peak eluted from HPLC analysis requires calibration which can be difficult for those compounds that are "unknown". DNPH reagent was used for the determination of hydroxymethylfurfural in honey and fruit juice with monitoring by HPLC [12,13]. DNPH was also used for the colorimetric analysis of flavonoids in honey $[14,15]$.

\subsection{Assay Characteristics}

Two of three methods evaluated in this study proved to be effective. DNPH method I [9] produced color instability most likely due to precipitate formation at room temperature (18 $20^{\circ} \mathrm{C}$ ). DNPH method II involved the use $\mathrm{NaOH}$ for color stabilization [10]. The calibration characteristics for NAC and DNPH assays are compared in Table 1.

\section{Table 1. Calibration parameters for methylglyoxal analysis using $\mathrm{N}$ - acetylcysteine (NAC) or 2, 4-dinitrophenylhydrazine (DNPH) reagent}

\begin{tabular}{|c|c|c|}
\hline Parameter & NAC & DNPH \\
\hline $\mathrm{R}^{2}$ & 0.99 & 0.97 \\
\hline$\varepsilon\left(\mathrm{M}^{-1}, \mathrm{~cm}^{-1}\right)$ & $287 \pm 11$ & $14189 \pm 498$ \\
\hline $\operatorname{MDC}(\mathrm{M})^{*}$ & $0.18 \times 10^{-3}$ & $7.3 \times 10^{-6}$ \\
\hline ULL (M) & $4.0 \times 10^{-3}$ & $83.0 \times 10^{-6}$ \\
\hline Day/Day & 16.0 & 18.3 \\
\hline Precision (\%) & & \\
\hline \multicolumn{3}{|c|}{$\begin{array}{c}{ }^{*} \text { Concentrations are for the reaction vessel. The pre- } \\
\text { diluted values were } 3.6-80 \mathrm{mM}(\mathrm{NAC}) \text { or } 0.12-9.6 \mathrm{mM} \\
(\mathrm{DNPH} \text { method). } \varepsilon=\text { molar absorptivity, } \mathrm{MDC}= \\
\text { minimum detectable concentration, ULL = upper limit } \\
\text { of linearity }\end{array}$} \\
\hline
\end{tabular}

The absorptivity (measure of sensitivity) and MDC for methylglyoxal were 50-fold and 25-fold greater for the DNPH compared to the NAC method (Table 1). However, values for ULL were 50 -fold greater using the NAC compared to the DNPH. The NAC results agree with previous reports [8]. The absorptivity for $\mathrm{DNPH}$ reaction with pyruvate was $\sim 10303 \mathrm{M}^{-1} \mathrm{~cm}^{-1}$ [10] compared to $14189 \mathrm{M}^{-1} \mathrm{~cm}^{-1}$ for methylglyoxal (pyrulvaldehyde) from this study (Table 1).

From (Fig. 1) NAC and DNPH assays had low interference from reducing sugars (fructose), glyoxal and 3-DG. Honey contains $\sim 80 \%$ fructose and glucose by dry-weight. A short reaction time and low temperatures (10 $\mathrm{min}$, $3^{\circ} \mathrm{C}$ ) probably expl ain the low responsiveness of DNPH towards reducing sugars [16]. Interestingly, pyruvate produced a DNPH response only slightly lower than methylglyoxal [9]. The present the study did not evaluate dihydroxyacetone reaction with DNPH or NAC $[17,18]$.

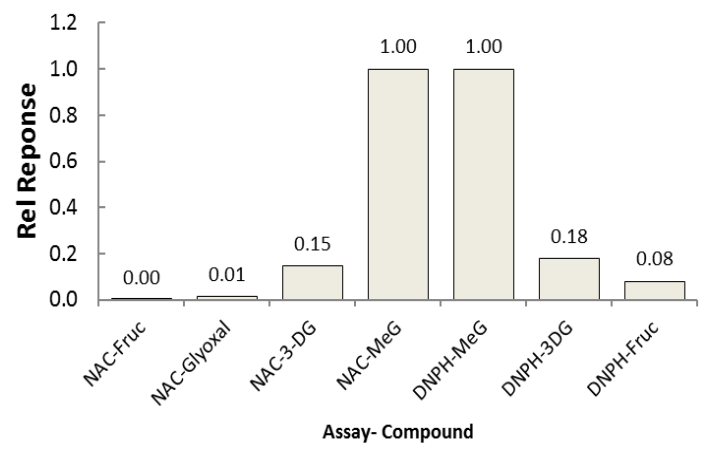

Fig. 1. Relative responses for some (di) carbonyl compounds using n-acetylcysteine (NAC) or 2, 4-dinitropheynlhydrazine (DNPH) assays

Test compounds were fructose (Fruc), glyoxal, 3deoxy-D-glucosone (3-DG), or methylglyoxal (MeG) at $0.5 \mathrm{mM}$. Data shows means $\pm S E M$ of 3 replicates. Rel Response $=$ absorbance for test compound divided by the absorbance from $\mathrm{MeG}$

\subsection{Methylglyoxal Equivalence for Honey}

Fig. 2 shows values for methylglyoxal equivalence determined using NAC or DNPH reagents for Manuka honey rated UMF $5+$ to $18+$. The term "equivalence" is used because NAC and DNPH tests are not specific for methylglyoxal.

Previous tests using 21 commercial honey samples showed there were four major dicarbonyl compounds indicated as; 4hydroxymethyl furfural $(0.66-44 \mathrm{mg} / \mathrm{kg})$, glyoxal $(0,2-2.7 \mathrm{mg} / \mathrm{kg})$, methylglyoxal $(0.4-5.4 \mathrm{mg} / \mathrm{kg})$ 
and 3-DG $(79-1266 \mathrm{mg} / \mathrm{kg})$. The levels for 4hydroxymethyl, furfural and 3-DG could vary during processing or storage conditions [3]. Another study involving 40 commercial honeys from 12 floral origins confirmed earlier reports for glyoxal $(0.1-10.9 \mathrm{mg} / \mathrm{kg})$, methylglyoxal $(0.2-2.9$ $\mathrm{mg} / \mathrm{kg}$ ) and 3-DG (75.9 - $808.6 \mathrm{mg} / \mathrm{kg}$ ) [19]. Five carbonyl compounds were listed from honey as 2, 3-butanedione, glucosone, 3-deoxyglucose, glyoxal, and methylglyoxal [20].

Manuka honey has about 20-fold higher concentration for methylglyoxal compared to other honey. Analysis of 49 samples of Manuka honey with UMF rating +5 to $30+$ showed methylglyoxal levels of $38-725 \mathrm{mg} / \mathrm{kg}$ or $46-828$ $\mathrm{mg} / \mathrm{kg}$ using a refractive index or UV detection for HPLC analysis. The UMF rating for Manuka honey was strongly correlated with methylglyoxal equivalence (Fig. 3) in agreement with prior reports [4].

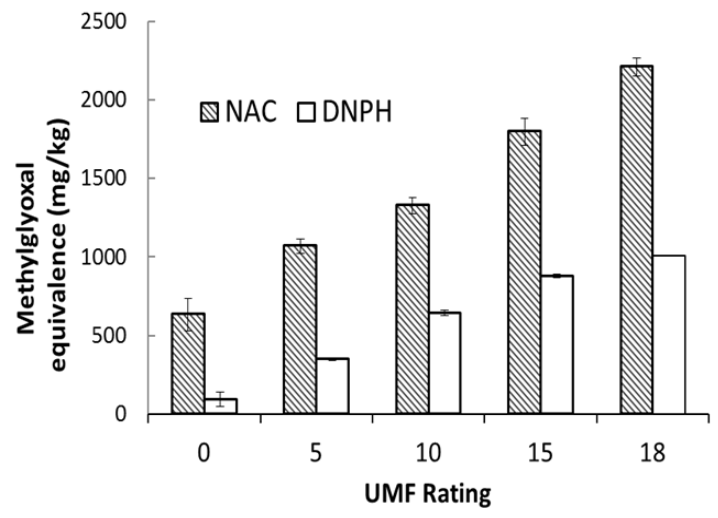

Fig. 2. Dicarbonyl compound from Manuka honey expressed as methylglyoxal equivalence

Results cited as methylglyoxal equivalence $(\mathrm{mg} / \mathrm{Kg}$ honey) using $n$-acetylcysteine (NAC) or 2, 4dinitrophenylhydrazine reagent. The unique Manuka factor (UMF) of honeys were "zero" (0) or standard supermarket honey, or 5+ (5), 10+ (10), 15+ (15) or $18+(18)$ for Manuka honey. Data shows means \pm SEM of 6 replicates determined on 2 or more separate days

Dihydroxyacetone (DHA) seems to be the precursor for methylglyoxal within Manuka honey [21]. Levels of DHA were higher for fresh Manuka honey but converted gradually to methylglyoxal with ageing. The DHA concentration for commercial Manuka honey ranged from $600-1200 \mathrm{mg} / \mathrm{kg}$ compared to methylglyoxal levels of 70 to $700 \mathrm{mg} / \mathrm{kg}[22,23]$. Interestingly, the DNPH reagent flavonoids analysis showed that Manuka honey had 11.6 $\mathrm{mg} / \mathrm{kg}$ [24] which is 2-orders of magnitude lower than the levels methylglyoxal and 3-DG.

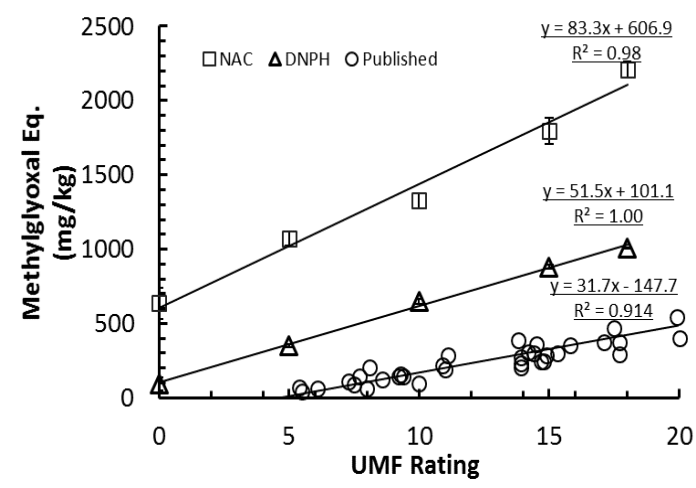

Fig. 3. Effect of UMF rating on methylglyoxal equivalence $(\mathrm{mg} / \mathrm{kg})$ for Manuka honey samples evaluated using DNPH and NAC assays

For comparison, Graph shows published HPLC data for methylglyoxal [4]. Data shows means \pm SEM of 6 replicates determined on 2 or more separate days

Processing and storage affects the net concentration of dicarbonyl compounds, so comparing values for honey samples used in the present study with values from the literature will not be straightforward $[22,23]$; ideally the current methods should undergo validation by comparing with HPLC analysis in-house. It seems both DNPH and NAC assays produce higher (methylglyoxal equivalence values compared with concentrations, reported by HPLC (Fig. 3). Colorimetric analysis reflects the concentration of each dicarbonyl compound within honey, their rate or extent of reaction with NAC or DNPH, and also the molar absorptivity of reaction products formed [17]. Using DNPH, for instance the methylglyoxal equivalence contribution due to $3-\mathrm{DG}$ would represent $18 \%$ of the actual concentration of this agent (Fig. 2).

The results obtained with NAC or DNPH differed by about 2-fold (Fig. 3) which remains puzzling. Assuming methylglyoxal exists as a reversibly bound form within physiological systems [17], the current results imply that NAC reagent is able to register higher available methylglyoxal as compared with DNPH. It has been shown at $\mathrm{pH}$ 7 that methylglyoxal reacts rapidly with NAC within seconds whilst the reactions with arginine (and other nitrogen-based nucleophiles) occur over a significantly longer time frame [17]. Interestingly, using values for the MDC reported in Table 1, the DNPH and NAC methods could 
detect a minimum methylglyoxal equivalence corresponding to $0.37 \mathrm{mg} / \mathrm{kg}$ (honey) and 9.1 $\mathrm{mg} / \mathrm{kg}$ (honey), respectively. The DNPH method probably has the requisite sensitivity for general applications to other honeys though these tend to have lower methylglyoxal content compared to manuka honey.

\section{CONCLUSIONS}

Colorimetric methods are proposed for rapidly monitoring methylglyoxal equivalences in manuka honey. Both the NAC and DNPH assays appear to be selective for methylglyoxal, but with some responsiveness to glyoxal, or 3-DG. The DNPH method was more sensitive compared to the NAC method and the former uses visible rather than UV absorbance detection. Simplicity and rapidness are important elements of the proposed method. In terms of limitation, the dayto-day precision is currently rather low. Work is underway to achieve practical improvements to the proposed assay. Further research is needed also to understand the sensitivity differences for NAC or DNPH regents when applied to honey. It is particularly urgent that the current method should be tested with other floral honey in addition to manuka honey. Finally, method validation against HPLC analysis would be useful [18]. Subject to further refinements the proposed methods could allow rapid screening for high methylglyoxal honey.

\section{COMPETING INTERESTS}

Authors have declared that no competing interests exist.

\section{REFERENCES}

1. Nikolov ZL. A method for the determination of $\alpha$-dicarbonyl compounds. J Dairy Sci. 1989;72(10):2474-77.

DOI: http://dx.doi.org/10.3168/jds.S00220302(89)79387-5

2. Degen J, Hellwig $M$, Henle T. 1,2dicarbonyl compounds in commonly consumed foods. J Agric Food Chem. 2012;60(28):7071-79. PMID: 22724891.

3. Weigel KU, Opitz T, Henle T. Studies on the occurrence and formation of 1,2dicarbonyls in honey. Eur Food Res Technol. 2004;218(2):147-151.

4. Adams CJ, Boult $\mathrm{CH}$, Deadman BJ, Farr JM, Grainger MNC, Manley-Harris M, Snow MJ. Isolation by HPLC and characterisation of the bioactive fraction of New Zealand Manuka (Leptospermum scoparium) honey. Carb Res. 2008;343(4): 651-659. PMID: 18194804.

5. Mavric E, Wittmann S, Barth G, Henle T. Identification and quantification of methylglyoxal as the dominant antibacterial constituent of Manuka (Leptospermum scoparium) honeys from New Zealand. Mol Nutr Res. 2008;52(4): 483-489. PMID: 18210383.

6. Atrott J, Henle T. Methylglyoxal in manuka honey - correlation with antibacterial properties. Czech J Food Sci. 2009;27: S163-S165.

7. Kwakman PHS, Velde AA, te Boer $L$, de Vandenbroucke-Grauls CMJ E, Zaat SAJ. Two major medicinal honeys have different mechanisms of bactericidal activity. PLoS ONE. 2011;6(3):2011. PMCID:PMC 3048876.

8. Wild R, Ooi L, Srikanth V, Munch G. A quick, convenient and economical method for the reliable determination of methylglyoxal in millimolar concentrations: The N-acetyl-L-cysteine assay. Anal Bioanal Chem. 2012;403(9):2577-81 . PMID: 22580513.

9. Gilbert RP, Brandt RB. Spectrophotometric determination of methylglyoxal with 2,4dinitrophenylhydrazine. Anal Chem. 1975;47(14):2418-22.

DOI: $10.1021 / \mathrm{ac} 60364 \mathrm{a} 003$

10. Anthon GE, Barrett DM. Modified method for the determination of pyruvic acid with dinitrophenylhydrazine in the assessment of onion pungency. J Sci Food Agric. 2002;83:1210-1213.

DOI: $10.1002 /$ jsfa. 1525

11. Bolanos de la Torre AA, Henderson T, Nigam PS, Owusu-Apenten RK. A universally calibrated microplate ferric reducing antioxidant power (FRAP) assay for foods and applications to Manuka honey. Food Chem. 2015;174:119-123. PMID: 25529660

12. LoCoco F, Valentini C, Novelli V, Ceccon L. High-performance liquid chromatographic determination of 2-furaldehyde and 5hydroxymethyl-2-furaldehyde in honey. J Chromatogr A.1996;749(1-2):95-102. DOI: 10.1016/0021-9673(96)00392-5

13. Lo Coco F, Novelli V, Valentini C, Ceccon L. High-performance liquid chromategraphic determination of 2-furaldehyde and 5-hydroxymethyl-2-furaldehyde in fruit 
juices. J Chromatogr Sci. 1997;35(12): 578-83. PMID: 9397542.

14. Chua LS, Rahaman NL, Adnan NA, Eddie Tan TT. Antioxidant activity of three honey samples in relation with their biochemical components. J Anal Methods Chem. 2013;313798. Epub 2013 Aug 21. PMCID: PMC3763360.

Doi: $10.1155 / 2013 / 313798$

15. Pontis JA, Alves da Costa LAM, Reis da Silva SJ, Flach A. Color, phenolic and flavonoid content, and antioxidant activity of honey from Roraima, Brazil. Food Sci Technol. 2014;34(1):69-73.

Available:http://dx.doi.org/10.1590/S010120612014005000015.

16. Roe JH. Comparative analyses for ascorbic acid by the 2,4dinitrophenylhydrazine method with the coupling reaction at different temperatures: a procedure for determining specificity. $J$ Biol Chem. 1961;236:1611-3. PMID: 13742654.

17. Lo TW, Westwood ME, McLellan AC, Selwood T, Thornalley PJ. Binding and modification of proteins by methylglyoxal under physiological conditions. A kinetic and mechanistic study with $\mathrm{N}$ alphaacetylarginine, $\mathrm{N}$ alpha-acetylcysteine, and $\mathrm{N}$ alpha-acetyllysine, and bovine serum albumin. J Biol Chem. 1994;269(51): 32299-305. PMID: 7798230.

18. Underwood JC, Lento HG. Some physical characteristics of the 2, 4-dinitrophenyl hydrazine and semicarbazide derivatives of three-carbon carbonyls. Anal Chem. 1960;32(12):1656-1658.

DOI: $10.1021 / \mathrm{ac} 60168 \mathrm{a} 030$
19. Arena E, Ballistreri G, Tomaselli F, Fallico B. Survey of 1,2-dicarbonyl compounds in commercial honey of different floral origin. $J$ Food Sci. 2011;76(8):C1203-C1210. PMID: 22417585.

20. Marceau E, Yaylayan VA. Profiling of alpha-dicarbonyl content of commercial honeys from different botanical origins: Identification of 3, 4-Dideoxyglucoson-3ene (3, 4-DGE) and related Compounds. J Agric Food Chem. 2009;57(22):1083710844. PMID: 19874027.

21. Adams CJ, Manley-Harris M, Molan PC. The origin of methylglyoxal in New Zealand Manuka (Leptospermum scoparium) honey. Carb Res. 2009;344(8): 1050-1053. PMID: 19368902.

22. Atrott J, Haberlau S, Henle T. Studies on the formation of methylglyoxal from dihydroxyacetone in Manuka (Leptospermum scoparium) honey. Carb Res. 2012;361:7-11. PMID: 22960208.

23. Windsor S, Pappalardo M, Brooks $P$, Williams S, Manley-Harris M. A convenient new analysis of dihydroxyacetone and methylglyoxal applied to Australian Leptospermum honeys. J Pharmacognosy Phytother. 2012;4(1):6-11.

DOI: $10.5897 / J P P 11.025$

24. Chan CW, Deadman, BJ, Manley-Harris M, Wilkins AL, Alber DG, Harry E. Analysis of the flavonoid component of bioactive New Zealand Manuka (Leptospermum scoparium) honey and the isolation, characterisation and synthesis of an unusual pyrrole. Food Chem. 2013;141(3): 772-81. PMID: 23870890.

(0) 2016 Kwok et al.; This is an Open Access article distributed under the terms of the Creative Commons Attribution License (http://creativecommons.org/licenses/by/4.0), which permits unrestricted use, distribution, and reproduction in any medium, provided the original work is properly cited.

Peer-review history:

The peer review history for this paper can be accessed here: http://sciencedomain.org/review-history/15026 